\title{
Comparative Analysis of Support Vector Machine and EGARCH Modelling of Zenith Bank PIc. Stock Price on Economic Growth in Nigeria
}

\author{
Alhaji, Ismaila Sulaiman ${ }^{* 1}$, Nweze N. O $^{1} .$, Abubakar, Muhammad Auwal ${ }^{1}$ \\ ${ }^{1}$ Department of Statistics, \\ Nasarawa State University \\ Keffi, Nigeria
}

Email: alhajiismail1985@gmail.com

\begin{abstract}
In this $21^{\text {st }}$ century, stock exchange has become a crucial and determining factor for the global economy, any variability in this market affects personal, corporate financial activities and the economic growth a country. A lot of analysis using different models were explored by several authors. However, this study set out to investigates the statistical behaviour of Zenith Bank PLC stock price using Support Vector Machine (SVM) and EGARCH Model on economic growth in Nigeria by adopting quantitative techniques using the causal-comparative research method. The findings from this research shows a coefficient of the Zenith bank Low stock price at (0.546945) and high stock price at (0.453562) which indicates that low stock price is insignificant because is less than $a=0.05$, while high stock price of greater than $a=0.05$ is significant to predict the Zenith bank stock price. Findings from the study has further revealed that SVM mode approach is more appropriate than EGARCH model and recommends that stockholders, financial analyst and researchers who are investing in stock market should adapt the SVM model approach to determine the volatility rate or level of stochastic in the financial time series data.
\end{abstract}

Keywords: Stock Price, Support Vector Machine (SVM), EGARCH Model, Stock Exchange, Economic Growth

\section{INTRODUCTION}

For over 50 years, the stock exchange has been an indispensable vehicle that has contributed to the development of Nigerian financial Institutions and the capital markets. The Nigerian Capital Market NCM was deregulated in 1993. And in 1995, certain laws were repealed in favor of unrestricted foreign investors participation. Since then, foreign capital flows into the NCM have continued to rise, in the form of foreign portfolio investment. The Nigerian Stock Exchange (NSE) is governed by a National Council (Board of Directors). The Council has an oversight of all the dealings of the Exchange. The history of the council demonstrates diverse professional representation, as provided by the memorandum and articles of association of the exchange. According to NSE (2012), NSE continues to evolve to meet the needs of its valued customers and to achieve the highest level of competitiveness. The NSE operates fair, orderly and transparent markets that bring together the best of African enterprises, involving both local and global investors communities. The Exchange is poised to champion the acceleration of Africa's economic development, and to become "the Gateway to African Markets". Stock exchange market plays a vital role towards Nigerian economic growth. 
Essentially, stock exchange includes an exchange between stock brokers and traders through buying and selling of stocks (shares), bonds and other securities. In any economy, stock exchange also provides facilities for issue and revitalization of securities and other financial instruments and capital events including the payment of income and dividends (Diamond, 2000).

In the same vein, the NCM of NSE is a major player in the Nigeria economy. The instruments or securities traded in the capital market are called capital market instruments. Nevertheless, the capital market has both the stock exchange- security base segment and market for long term loans non-securities based segment. There are three (3) major categories of securities; these include preference shares, ordinary shares and debt instruments. Some of the other principal and active market operators in the Nigerian Stock Market include Stockbrokers, Investment Advisers, Issuing houses, Registrars, Fund Managers, Financial Advisers etc. (Olowe, et al., 2011).

Several models have been used to explain the correlation between the economic growth and stock returns. For instance, the Garch model which was proposed by Black in 1976 has been proven to be very useful in capturing symmetric effect of volatility. The model assumes that positive and negative error terms have a symmetric effect on volatility, i.e., good and bad news have the same size of effect on volatility in the model. In practice, this assumption is frequently violated by stock returns, which tends to increase the volatility (Christopher \& Kenneth, 2017). The model is limited to symmetric effect of volatility which led to an extension by Bolerslev (1986) and Taylor (1986) using Autoregressive Moving Average (ARMA) formulation. The extended model is called the Generalized ARCH Model. The model use conditional variance as a function of its lagged values as well as squared lagged values of the disturbance term. The stock exchange has become a crucial factor of the global economy, and any variability in this market affects personal and corporate financial activities and the economic growth of a country. The daily behavior of the market prices revealed that the future stock prices cannot be predicted based on past movements.

Mandelbrot (1963) applied the beta coefficient to measure the returns from the Nigeria Stock Exchange (NSE). The result shows that the stock market returns is largely counter cyclical being larger in bad times than in good times. Thus, stock expected much less returns during expansions than they increase during recessions. This is as results of the requirement of the investors return is not only counter cyclical but also asymmetrically related to the growth of the business cycle which happens when the investors expected return to invest in the stock market increase more in bad times than they decrease in good time.

Chaudhuri and Smiles (2004) used multivariate co-integration methodology to investigate the long-run relationship between stock returns and gross domestic product (GDP). The study established existence of a long-run relation between stock returns and gross domestic product (GDP). The error correction procedure indicated that the stock returns are connected to the changes in GDP. Alajekwu and Achugbu (2012) found out that market capitalization and value traded ratios have a very weak negative correlation with economic growth while turnover ratio has a very strong positive correlation with economic growth.

\section{METHODOLOGY}

In this study we used the Support Vector Machine SVM-based approach. the SVM-based method is multiscale volatility model that can relax a number of restrictive assumptions for estimating the EGARCH model. SVM is a combination of a kernel-based approach and a Structural Risk Minimization (SRM) principle (Vapnik, 1995). 


\section{Statistical Models of NSE and Pricing}

Over the years, several models have been used to model the NSE and pricing. We shall explore the EGARCH Model.

\section{Estimated GARCH- Family Model}

The Estimated GARCH-Family model

$$
\begin{aligned}
& \varepsilon_{t}^{2}=\alpha_{o}+\sum_{k=1}^{q} \alpha_{1}+\varepsilon_{t-1}^{2}+\sum_{k-j}^{q} \beta_{j} \varepsilon_{t-1}^{2} \\
& \log \left(\sigma_{t-1}^{2}\right)=\beta_{o}+\sum_{k=1}^{q} \alpha_{1} \varepsilon_{t-1}\left|\gamma_{1} \varepsilon_{t-1}\right|+\sum_{j+1}^{p} \beta_{j} \log \left(\sigma_{t-1}^{2}\right) \\
& \varepsilon_{t}^{2}=\beta_{o}+\alpha_{1} \varepsilon_{t-1}^{2}+\gamma_{1} I_{t-1} \varepsilon_{t-1}^{2}+\beta_{1} \varepsilon_{t-1}^{2}
\end{aligned}
$$

\section{To Estimate the Link between NSE and Economic Growth}

To achieve this objective, we shall use the long-term regression model given by

$$
\begin{aligned}
& L_{n} \gamma_{t}=\phi_{o}+\phi_{1} F D I_{t}+\phi_{2} G E X P_{t}+\phi_{3} L_{n} M C_{t}+\phi_{4} L_{n} C P S_{t}+\phi_{5} \text { SMDIND }_{t}+\varepsilon_{t} \\
& L_{n} \gamma_{t}=\sigma_{o}+\sigma_{1} F D I_{t}+\sigma_{2} L_{n} G E X P_{t}+\sigma_{3} L_{n} M C_{t}+\sigma_{4} L_{n} C P S_{t}+\sigma_{5} S M I N D_{t}+\varepsilon_{t} \\
& L_{n} \gamma_{t}=\theta_{o}+\theta_{1} F D I_{t}+\theta_{2} L_{n} G E X P_{t}+\theta_{3} L_{n} M C_{t}+\theta_{4} L_{n} C P S_{t}+\theta_{5} \text { SMDIND }_{t}+\varepsilon_{t}
\end{aligned}
$$

where, $\gamma_{t}=$ Real total GDP exchanging the contributions from the oil and financial sectors. $M C_{t}=$ real stock market capitalization, $V T_{t}=$ real stock where traded, $G E X P_{t}=$ real government expenditure, $F D I_{t}=$ real credit to the private sector, $S M D I N D=$ stock market development index $, \phi_{0}, \sigma_{0}$, and $\theta_{0}$ are constant parameters, $\phi_{i}, \sigma_{i}$, and $\theta_{i}$ are long term Blasticities / coefficients, $\varepsilon_{t}=$ The noise error term, $L_{n}=$ Natural $\log$ Operator

\section{To develop a Volatility Model}

We shall use the multi-scaling approach to develop a new model for NSE pricing. In the multi-scaling approach, with the assumption that the GDP is denoted by $\Upsilon_{t}$ is a linear transform of a collection of independent variables $\left(M C_{t}, V T_{t}, G E X P_{t}, F D I_{t}, S M D I N D\right)$ given as

$$
\gamma_{t}=\psi^{-1} \vec{C}
$$

where, $\Upsilon_{t}$ is the real GDP, $\psi^{-1}$ is the inverse wavelet transform, $\vec{C}=\left\{c_{k}\right\}$ is a vector of random variables which are assumed to be independent.

The distribution of each $c_{k}$ is $P_{k}($.$) and since the c_{k}{ }^{\prime} s$ are independent, it follows that:

$$
P(\vec{C})=\prod_{k} P_{k}\left(C_{k}\right)
$$

In particular we shall use SVM-based approach which is a combination of a kernel-based approach and a structural risk minimization (SRM) principle (Vapnik, 1995; 1998).

We shall use the $\varepsilon$-insensitive loss function $(\varepsilon-\mathrm{ILF})$ which is similar to loss functions used in the field of robust statistics (Valeriy \& Supriya, 2003). It has been shown by Pontil et al. (1998) that the use of $\varepsilon$-ILF is justified under assumption that the noise is a superposition of Gaussian processes. The heteroskedastic market data was successfully modeled using this noise model, and $\varepsilon$-ILF will be used in our volatility model.

We assumed that volatility $v$ can describe a nonlinear function $\mathrm{F}$ of time series of return $\mathrm{r}$ which is given by

$v_{i}^{2}=F\left(r_{i-1}, r_{i-2}, \ldots \ldots, r_{n}\right)$

where, $F$ is any nonlinear function which include multiscale dependencies in a more general form than HARCH model. This is similar to HARCH model which can be useful to directly study influence of different market components. Thus this is given explicitly as 
$v_{i}^{2}=F\left[r_{i-1}\left(r_{i-1}+r_{i-2}\right), \ldots .,\left(\sum_{j=1}^{n} r_{i-1}\right)\right]$

where, $i-j$ is the time lag interval denoted by $\left(t_{i-j} d t\right)$

Also to ensure that trained SVM model will always output non-negative numbers for $v^{2}$. We shall achieve by choosing mapping function as

$v_{i}^{2}=\exp \left[F\left(r_{i-1}, r_{i-2}, \ldots \ldots, r_{i-n}\right)\right]$

To Apply the Resulting Model to Predict Stock Price of Nigeria Economy

To achieve this objective, we shall use the developed model to predict the stock price of Nigeria economy using data from NSE and CBN.

\section{RESULTS AND DISCUSSION}

\section{Support Vector Machine}

Table 1 below gives the descriptive statistics of the daily Zenith bank stock

Table 1 Descriptive Statistics

\begin{tabular}{|c|c|c|c|c|c|c|}
\hline Role & Name & $\mathbf{N}$ & Type & Statistics & Range & missing \\
\hline Regular & Price & 4027 & Numeric & $\operatorname{avg}=19.570+/-4.501$ & {$[9.000 ; 33.510]$} & 0 \\
\hline Regular & Open & 4027 & Numeric & $\operatorname{avg}=19.573+/-4.570$ & {$[0.000 ; 34.200]$} & 0 \\
\hline regular & High & 4027 & Numeric & $\operatorname{avg}=19.807+/-4.549$ & {$[9.440 ; 34.200]$} & 0 \\
\hline regular & Low & 4027 & Numeric & $\operatorname{avg}=19.351+/-4.465$ & {$[8.830 ; 32.550]$} & 0 \\
\hline regular & Change & 4027 & Numeric & $\operatorname{avg}=0.001+/-0.023$ & {$[-0.130 ; 0.102]$} & 0 \\
\hline
\end{tabular}

The descriptive statistics indicate that 4027 sample of Zenith Bank daily stock price from 2nd January 2004 to $2^{\text {nd }}$ January 2020 with a period of 16 years. Where the Zenith Bank stock price has an average of 19.57 stock price index and the price ranges from minimum value 9.00 to the maximum value of 33.510. The open price index, High price index, Low price index and percentage change price index has an average of $(19.573,19.807,19.351,0.001)$ whereas the minimum and maximum value for open price index $(0.000 ; 34.20)$ while high price index $(9.44 ; 34.200)$ while Low price index $(8.830 ; 32.550)$ and the minimum and maximum value for percentage change in price index $(-0.130 ; 0.102)$.

\section{Kernel Model}

The kernel model given in below tables, shows the activities of support vectors in the kernel, so also the vectors $\mathrm{w}\left(a_{1}\right), \mathrm{w}\left(a_{2}\right), \mathrm{w}\left(a_{3}\right)$ and $\mathrm{w}\left(a_{5}\right)$ are positive while vector $\mathrm{w}\left(a_{4}\right)$ is negative so we conclude that since most of the vectors are positive it implies that support 
vectors model are significant at $a=0.01$ level. The kernel model indicate the activities of vector under the support vectors machine where the total number of support vectors are 200, the weight of attributes of the five vectors $\left.a_{1}=0.395, a_{2}=0.639, a_{3}\right) \backslash=0.249, a_{4}=$ $0.073, a_{5}=0.043$ and the kernel activities of the vectors in the model is 1000 where cluster 0 $=285$ items, cluster $1=121$ items, cluster $2=510$ items and clusters $3=84$ items given the total activities of 1000 support vectors activities.

The vectors $a_{1}, a_{2}, a_{3}, a_{5}$ are significant at $a=0.01$ level while vector $a_{4}$ is not significant which indicates that Zenith bank low stock price and High stock price can jointly influence Zenith bank stock price.

Table 2 SVM Kernel Cluster Tree

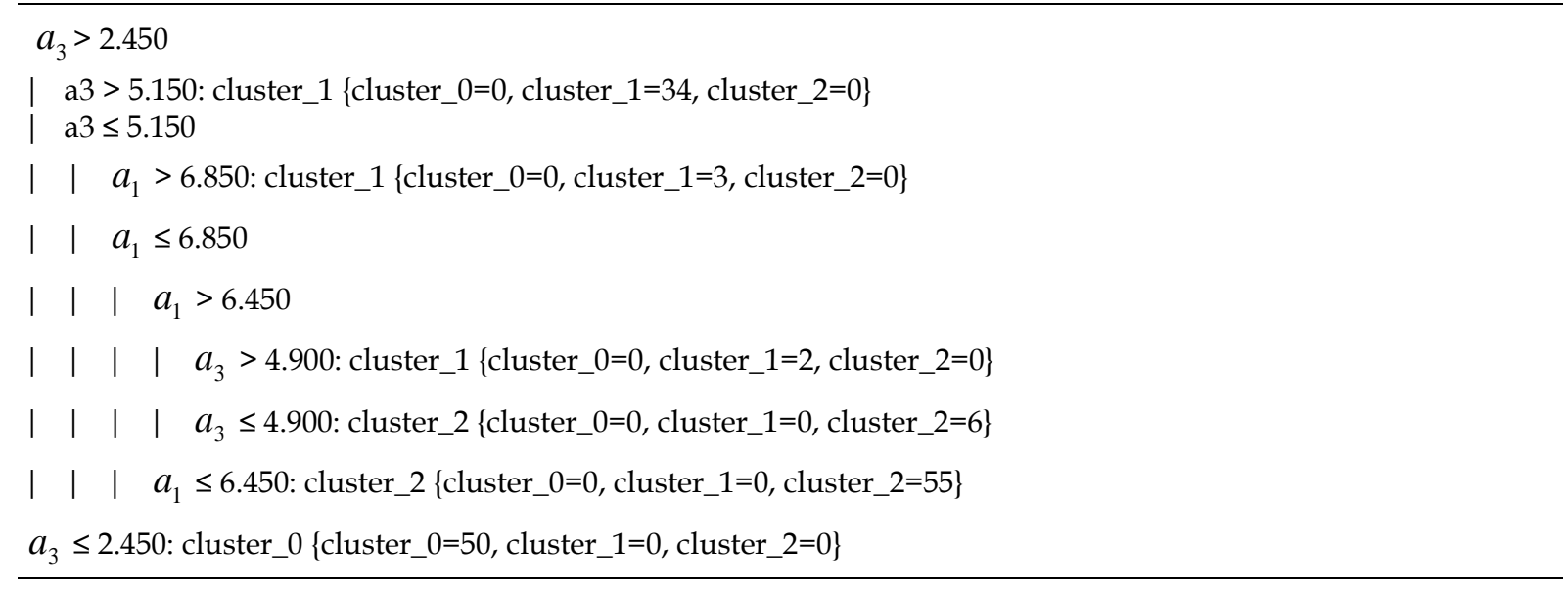

The SVM Kernel tree indicate that vector a3 and a1 are the dominant vectors but vector a 3 is the most dominant vector in the Kernel Cluster tree.

Note that vector

$a_{1}=$ Zenith bank stock price

$a_{2}=$ Zenith bank low stock price

$a_{3}=$ Zenith bank High stock price

$a_{4}=$ Zenith bank percentage change of stock

$a_{5}=$ Zenith bank Open price

This implies that vector a3 which represent Zenith bank High stock price has influence over the vector a1=Zenith bank actual stock price.

TABLE 3: K Means analysis

\begin{tabular}{|c|c|c|c|c|}
\hline Component & $\begin{array}{l}\text { Singular } \\
\text { Values }\end{array}$ & $\begin{array}{l}\text { Proportion } \\
\text { Singular } \\
\text { Values } \\
\end{array}$ & $\begin{array}{l}\text { Cumulative } \\
\text { Singular } \\
\text { Values } \\
\end{array}$ & $\begin{array}{l}\text { Cumulative } \\
\text { Proportion } \\
\text { Singular } \\
\text { Values } \\
\end{array}$ \\
\hline SVD 1 & 95.951 & 0.806 & 95.951 & 0.806 \\
\hline SVD 2 & 17.723 & 0.149 & 113.674 & 0.955 \\
\hline SVD 3 & 3.469 & 0.029 & 117.143 & 0.984 \\
\hline SVD 4 & 1.879 & 0.016 & 119.022 & 0.296 \\
\hline
\end{tabular}


Table 4: SVD Vectors

Total

Attribute SVD Vector1 SVD Vector2 SVD Vector3

\begin{tabular}{lllll}
\hline$a_{1}$ & 0.751 & -0.286 & 0.499 & $\mathbf{0 . 9 6 4}$ \\
$a_{2}$ & 0.38 & -0.545 & -0.675 & $\mathbf{- 0 . 8 4}$ \\
$a_{3}$ & 0.513 & 0.709 & -0.055 & $\mathbf{1 . 1 6 7}$ \\
$a_{4}$ & 0.168 & 0.345 & -0.54 & $\mathbf{- 0 . 0 2 7}$ \\
Total & $\mathbf{1 . 8 1 2}$ & $\mathbf{0 . 2 2 3}$ & $\mathbf{- 0 . 7 7 1}$ & $\mathbf{1 . 2 6 4}$ \\
\hline
\end{tabular}

Similarly, K mean Analysis in table 3 indicates that SVD3 in table 4 is the most dominant vector against SVD1, SVD2, SVD4 because it has the highest Cumulative Proportion Singular Value (CPSV).

The SVD vectors table also shows that SVD 3 is the dominant vector model against SVD1, SVD2, SVD4 because it has the lowest value $=-0.771$ which is closer to 1 and attribute vector $\mathrm{a}_{3}$ is still the dominant vector because it has the highest value $=1.167$

The K means analysis further shows that support vector density (SVD3) which is the mass (weight) of vector $\left(a_{3}\right)$ shows that Zenith bank High stock price is the determine factor of vector a1=Zenith bank actual stock price.

Table 5 Multiple Label Learning

\begin{tabular}{|c|c|c|c|c|}
\hline & & \multirow{2}{*}{$\begin{array}{l}\text { True } \\
\text { Positive }\end{array}$} & True & Class \\
\hline & & & Negative & Precision \\
\hline Pred. Positive & & 114 & 14 & $91.14 \%$ \\
\hline Pred. Negative & 15 & & 127 & $89.44 \%$ \\
\hline Class Recall & & $90.57 \%$ & $90.07 \%$ & \\
\hline
\end{tabular}

The true positive and true negative label shows that support vector model is significant to model out zenith bank stock price since the true positive and the predictive positive class precision has the highest percent.

Table 6: Weighting Thresholds

Parameter Set

Parameter set:

Performance:

Performance Vector

-----classification error: 0.60\% +/- 0.92\% (mikro: 0.60\%)

Confusion Matrix:

True: negative positive

negative: $238 \quad 3$

positive: $0 \quad 259$

]

Selection weight $\quad=0.2$

Stacking Classification

\section{KNN Classification}

5-Nearest Neighbour model for classification.

The model contains 1000 examples with 5 dimensions of the following classes: 
negative $=238$

positive $=259$

The stacking classification of 5-Nearest neighbor model out rightly shows that confusion matrix indicate performance of vectors where the positive vectors $=259$ outshined the negative $=238$ vectors. This means that $\mathrm{a} 1=$ Zenith bank stock price has a jointly influence of both $\mathrm{a}_{2}$, $\mathrm{a}_{3}$ and $\mathrm{a}_{5}$ vectors.

Table 7: Linear Regression

\begin{tabular}{llllllll} 
Attribute & Coefficient & $\begin{array}{l}\text { Std. } \\
\text { Error }\end{array}$ & $\begin{array}{l}\text { Std. } \\
\text { Coefficient }\end{array}$ & Tolerance & t-Stat & P-value & Code \\
\hline att1 & 0.002 & 0.003 & 0.052 & 0.999 & 0.636 & 0.530 & \\
att3 & 0.004 & 0.003 & -9.302 & 1.000 & 1.519 & 0.164 & \\
att4 & 0.001 & 0.003 & -0.023 & 1.000 & 0.205 & 0.840 & \\
att5 & 0.004 & 0.003 & -0.764 & 0.999 & 1.499 & 0.171 & \\
(Intercept) & 0.650 & 0.015 & NaN & NaN & 43.158 & 0.000 & $*$ \\
& & & & & & &
\end{tabular}

Linear regression model indicates that the attributes $a_{1}, a_{2}, a_{3}, a_{4}$ are significant because the intercept is less than alpha $=0.05$ and its $p$-values is greater than $a=0.05$. So also the coefficient values, level of tolerance and the $t$-statistics are positive.

\section{GARCH Data Analysis; Zenith Bank Stock Price}

The Zenith Bank stock price Series plot indicate the daily stock price realized at the floor of the stock market at the close of each market day from the period of $2^{\text {nd }}$ January, 2004 to $11^{\text {th }}$ February, 2020 for 4027 market days. The stock price plot indicate that at $11^{\text {th }}$ January 2018 experience a very high stock price of 33.01 and at $16^{\text {th }}$ January, 2010 experience a close of a very high stock price of 33.51 respectively. So also 18 January, 2016 shows a very low stock price of $9.0,12^{\text {th }}$ February, 2008 also showed a very low stock price of 9.0 and $26^{\text {th }}$ January, 2004 also showed a very low stock price of 9.29 .

\section{TABLE A8: Estimating GARCH/TGARCH}

Dependent Variable: ZENITH_STOCK_PRICE

Method: ML ARCH - Normal distribution (BFGS / Marquardt steps)

Date: 03/20/21 Time: 12:41

Sample: 14027

Included observations: 4027

Convergence achieved after 32 iterations

Coefficient covariance computed using outer product of gradients

Presample variance: backcast (parameter $=0.7$ )

$\mathrm{GARCH}=\mathrm{C}(3)+\mathrm{C}(4)^{*} \mathrm{RESID}(-1)^{\wedge} 2+\mathrm{C}(5)^{*} \mathrm{GARCH}(-1)$

\begin{tabular}{lllll}
\hline \hline Variable & Coefficient & Std. Error & Z-Statistic & Prob. \\
\hline \hline LOW & 0.540620 & 0.006751 & 80.08373 & 0.0000 \\
HIGH & 0.459788 & 0.006496 & 70.78095 & 0.0000 \\
\hline \hline \multicolumn{7}{l}{ Variance Equation } & & \\
\hline \hline C & 0.007552 & 0.000521 & 14.48350 & 0.0000 \\
RESID $(-1)^{\wedge} 2$ & 0.275782 & 0.016597 & 16.61608 & 0.0000 \\
GARCH(-1) & 0.582935 & 0.017100 & 34.08974 & 0.0000 \\
\hline \hline
\end{tabular}




\begin{tabular}{llll} 
R-squared & 0.997693 & Mean dependent var & 19.57028 \\
Adjusted R-squared & 0.997692 & S.D. dependent var & 4.501259 \\
S.E. of regression & 0.216244 & Akaike info criterion & -0.383240 \\
Sum squared resid & 188.2143 & Schwarz criterion & -0.375416 \\
Log likelihood & 776.6529 & Hannan-Quinn criter. & -0.380467 \\
Durbin-Watson stat & 1.755646 & & \\
\hline \hline
\end{tabular}

The variance equation indicates that the coefficient (0.582935) which is the Garch Parameter and constant (0.007552) and the Arch effect (0.275782) is positive and is statistically significant at 0.01 level meaning that the Zenith Bank stock is asymmetric i.e Zenith bank Low stock price and High stock has effect on Zenith Bank Stock price.

The coefficient of the Zenith bank low stock price (0.546945) and high stock price (0.453562) indicates that low stock price is not significant because it is less that $a=0.05$ while Zenith bank high stock price is significant to predict the Zenith bank Stock Price because it is greater than $a=0.05$. Testing for Serial Correlation, Durbin Watson Test is use to test if Residuals $\left(\mathrm{R}^{2}\right)$ are correlated or not. $\mathrm{R}^{2}=0.997690=99.77 \%$ which is more than $50 \%$ indicate that Tgarch model fit well to represent Zenith bank stock price so also its Durbin Watson Test value 1.754072 since it is greater than $\alpha=0.01$. At probability of 0.000 indicates that T-garch is significant.

This shows that the result of the TGARCH model. The time varying volatility includes the constant (0.007552) the past (0.582935) and all the component which depends on past errors (0.275782). Finally the Zenith bank low stock price plus the High stock price value significantly can predict the actual (current) Zenith Stock price.

\section{CONCLUSION}

Our proposed study revealed that SVM forecasting the performance of EGARCH Model on economic growth where the open market has the high price index, the minimum and maximum value for percentage change in price index. This finding support the work of Alajekwu and Achugbu (2012) who found out that market capitalization and value traded ratios have a very weak negative correlation with economic growth while turnover ratio has a very strong positive correlation with economic growth. The finding also agreed with work of Eke (2016) who found out that the logistic distribution is better than the normal distribution in modeling the returns from the NSE due to its $p$ - value is greater than the $5 \%$ significance level alpha and also because of its minimum variance. discovering the best model for any time series, with good forecasting results with less prediction error, using the SVM model approach and some GARCH family model. further findings from the study revealed that Garch Parameter is positive and is statistically significant and Zenith Bank stock is asymmetric i.e zenith bank Low stock price and High stock has effect on Zenith Bank Stock price for economic growth. This finding disagreed with the work of Olowe (2011) who found out that the negative relationship between the market capitalization and the Gross Domestic Product (GDP) as well as a negative relationship between the turnover ratio and the GDP while a positive relationship was observed between the all-share index and the GDP. The finding later supports the work of Ofomata (2017) who found out that there is likelihood of each change in the stock prices, the drift and the volatility of the change were calculated which resulted to the formulation of stochastic differential equations.

First finding form the study revealed that SVM forecasting the performance of EGARCH Model on economic growth where the open market has the high price index and the minimum and maximum value for percentage change in price index. This finding support the work of Alajekwu and Achugbu (2012) who found out that market capitalization and 
value traded ratios have a very weak negative correlation with economic growth while turnover ratio has a very strong positive correlation with economic growth. Our findings also agreed with work of Eke (2016) who found out that the logistic distribution is better than the normal distribution in modeling the returns from the Nigeria stock exchange due to its $\mathrm{p}$ - value is greater than the $5 \%$ significance level alpha and also because of its minimum variance.

More findings from the study revealed that Garch Parameter is positive and is statistically significant and Zenith Bank stock is asymmetric i.e Zenith bank Low stock price and High stock has effect on Zenith Bank Stock price for economic growth. This finding is in slight disagrement with the work of Olowe (2011) who found out that the negative relationship between the market capitalization and the Gross Domestic Product as well as a negative relationship between the turnover ratio and the Gross Domestic Product while a positive relationship was observed between the all-share index and the Gross Domestic Product.

The research as a result recommended the following:

i. That stockholders, financial analysis and researchers who are investing in stock market should adapt the support vector machine model approach to determine the volatility rate or level of stochastic in the financial time series data using Kernel cluster model KNN classification, $\mathrm{K}$ means analysis and multiple labeling learning.

ii. Stockbrokers, Stock market investors and shareholders in Zenith Bank stock market, should not entertain investing in the Zenith Bank because in situation of any form of loss or volatility in the stock market, the Zenith bank stock returns have the ability to return to their middling price return and also the stock price has the potentials to increase in the future.

\section{ACKNOWLEDGEMENT}

We wish to express our gratitude to Dr. Maikudi K. Allahnana for his scholarly contribution and to the anonymous reviewers for their kind comments which generally improves the content of the manuscript.

\section{REFERENCES}

Anulika, A. A. (2017). Impact of the Nigerian stock exchange on economic growth. Munich Personal RePEc Archive. Retrieved from https://mpra.ub.uni-muenchen.de/75984/

Bachelier, L. (1964). Theorie de la Speculative Paris: Gauthier- Villar. Translated in Cooler

Bauer, H. \& Burckel, R. B. (1996). "Probability Theory", Berlin: De Gruyter. Retrieved from http:// search.ebscohost.com/login.aspx?direct $=$ true\&db=nlebk\&AN=560545\&site $=e d$ s-live

Bencivenga, V.R. \& Smith, B. D. (1991). Financial Intermediation and Endogenous Growth. Rev. Econ. Study, 58, 195-209.

Bollerslev, T. (1986). Generalized Autoregressive Conditional Heteroskedasticity. Journal of Econometrics, 31 (3): 307-327. doi:10.1016/0304-4076(86)90063-1.

Chaudhuri, K. \& Smiles, S. (2004). Stock Market and Aggregate Economic Activity; Evidence from Australia. Applied Financial Economics, 14, 121-129, degree of masters of Science in finance, University of Nairobi.

Diamond, P. A. (2000). What Stock Market Returns to Expect For The Future?" Social Security Bulletin, 63(2)

Ding, Z., Granger, C W. J. \& Engle, R. F. (1993). A Long Memory Property of Stock Market Returns and a New Model. Journal of Empirical Finance, 1, 83-106. 
Eke, C. N. (2016). Comparative Analysis of Normal and Logistic Distributions Modeling of Stock Exchange Monthly Returns in Nigeria (1995- 2014). International Journal of Business \& Law Research 4(4), 58-66

Emekekwue, P. (2009). Corporate Financial Management, Enugu. African Bureau of Education Sciences, 4, 34-45

Ezeoha, A., Ogamba, E. \& Onyiuke, N. O. (2009). Stock Market Development and Private Investment Growth in Nigeria. Journal of Sustainable Development in Africa, 11(2), 20 35.

Fama, E.F. \& French, K. R. (2004). The Behavior of Stock Market Prices, Journal of Business, 38, 34-105.

King, R.G. \& Levine, R. (1993). Finance and Growth: Schumpeter Might be Right. Q. J. Econ., $108,717-737$.

Levine, R. (1991). Stock Markets, Growth and Tax Policy. J. Financ., 64, 1445-1465.

Mahtadi, H. \& Agarwal, S. (2001). Stock Market Development and Economic Growth: Retrieved from Developing Countries. http://www.articlesbase.com/financearticles/stock-market-development-and-economic-growth-evidence-fromunderdeveloped-nation-nepal-1096815.html

Mandelbrot, B. (1963). The Variation of Certain Speculative Price. Journal of Business 36, 394439.

Merton, R. C., Brennan, M. J. \& Schwartz, E. S. (1977). The Valuation of American Put Options. Journal of Finance, 32 (2), 449-462.

Ndako, U. B. (2009). Stock Markets, Banks and Economic Growth: A Time-Series Evidence From South Africa.

http://www/africametrics.org/documents/conferences09/papers/Ndako-pdf.

Nelson, D. B. (1991). "Conditional Heteroskedasticity in Asset Returns: A New Approach" Econometrica, 59(2), 347-370.

Olowe, O., Matthew, O. \& Fasina, F. (2011). Nigerian Stock Exchange and Economic Development. Knowledge Management, Information Management, Learning Management, 1-25. 